\title{
Correlation between B-Type Natriuretic Peptide and N-Terminal pro-B-Type Natriuretic Peptide in a Large Japanese Population at Risk of Stage A Heart Failure
}

\author{
Mizuri Taki Satoshi Hoshide Ken Kono Kazuomi Kario \\ Division of Cardiovascular Medicine, Department of Medicine, Jichi Medical University \\ School of Medicine, Tochigi, Japan
}

\section{Keywords}

B-type natriuretic peptide $\cdot \mathrm{N}$-terminal pro-B-type natriuretic peptide $\cdot$ Stage A heart failure . High-risk population · Japanese population

\begin{abstract}
Background: The measurements of B-type natriuretic peptide (BNP) and N-terminal pro-Btype natriuretic peptide (NT-proBNP) are useful for ruling out heart failure and as prognostic markers in not only heart failure populations but also general populations. It is not clear whether these two biomarkers are elevated in parallel or associated with demographic characteristics in large populations at risk of stage A heart failure. Here we investigated the relationship between BNP and NT-proBNP and extended the evaluation of this association to known demographic disparities in stage A heart failure. Methods: Of 4,310 ambulatory patients, we analyzed the cases of the 3,643 (mean age $65 \pm 11$ years, 46\% male, and $79 \%$ on antihypertensive medication) patients whose serum BNP and NT-proBNP levels were both measured and who had a history of and/or risk factors for cardiovascular disease from the Japan Morning Surge-Home Blood Pressure (J-HOP) Study dataset. Results: The median (25th-75th percentiles) BNP and NT-proBNP values were 18.7 (9.3-38.5) pg/mL and 50.3 (25.597.4) $\mathrm{pg} / \mathrm{mL}$. There was a significant association between log-transformed BNP and log-transformed NT-proBNP $(r=818, p<0.001)$. A multiple linear regression analysis showed that logtransformed NT-proBNP was significantly associated with log-transformed BNP (beta coefficient $=0.774, p<0.001$ ). When stratified by demographic characteristics, these associations remained (all $p<0.001$ ). Conclusion: In a large Japanese population at risk of stage $A$ heart failure, there was a significant association between BNP and NT-proBNP after adjustment and stratification by demographics.


Taki et al.: Correlation between BNP and NT-proBNP

\section{Introduction}

The measurements of the serum levels of an individual's natriuretic peptide hormones, in particular B-type natriuretic peptide (BNP) and N-terminal pro-B-type natriuretic peptide (NT-proBNP), are established as useful biomarkers for ruling out heart failure [1, 2]. Both BNP and NT-proBNP have also been reported to be prognostic markers in not only heart failure populations but also general or hypertensive populations [3-5]. In some studies performing a head-to-head comparison of the diagnostic utility of BNP and NT-proBNP for the screening of left ventricular function and the prognostic power of cardiovascular prognosis, the utility of the two biomarkers was largely similar [6, 7]. However, BNP and NT-proBNP are released into the circulation with different biological activations, in which BNP has biological activity and NT-proBNP does not $[8,9]$. Both BNP and NT-proBNP are influenced by demographic characteristics such as age, gender, obesity, and renal function [10-13]. Few studies have been performed to determine whether BNP is elevated in parallel or associated with NT-proBNP in accord with demographic characteristics.

The management of stage A heart failure patients - who, with their cardiovascular risk factors, are at high risk of developing advanced heart failure - is one of the challenging issues in the field of cardiovascular disease (CVD) [14]. Although the use of BNP and NT-proBNP as biomarkers may be useful for risk stratification in this population, there have been no data explaining whether the correlation between BNP and NT-proBNP would differ according to the presence or absence of demographic risk factors for stage A heart failure.

In the present study, using the data of a large clinical population of patients who had more than one cardiovascular risk factor, we investigated the relationship between BNP and NT-proBNP levels and extended the examination of this association to known demographic disparities in stage A heart failure.

\section{Methods}

\section{Study Population}

We used the baseline data of the Japan Morning Surge-Home Blood Pressure (J-HOP) Study. The protocol of the J-HOP study has been published [15]. Briefly, the J-HOP study is a prospective observational study (University Hospital Medical Information Network Clinical Trials Registry, UMIN000000894) evaluating the use of home blood pressure (BP) measurements to predict cardiovascular events between January 2005 and May 2012 in 4,310 Japanese ambulatory patients who had a history of and/or risk factors for CVD as follows: hypertension, hyperlipidemia, diabetes, glucose intolerance, metabolic syndrome, chronic kidney disease (CKD), history of CVD, atrial fibrillation, current smoking, chronic obstructive pulmonary disease, or sleep apnea syndrome. All participants provided written informed consent for their data to be used, and the Institutional Review Board of Jichi Medical School approved the study.

Of the 4,310 patients enrolled in the J-HOP study, we excluded 667 patients for whom there was no data of either BNP or NT-proBNP. A final total of 3,643 patients was thus included in the present analysis. The diagnostic criteria of diabetes were defined as a fasting glucose level of $\geq 126 \mathrm{mg} / \mathrm{dL}$ and/or a casual glucose level of $\geq 200 \mathrm{mg} / \mathrm{dL}$ or treated diabetes. Hyperlipidemia was defined as a total cholesterol level of $\geq 240 \mathrm{mg} /$ $\mathrm{dL}$ or treated hyperlipidemia. CKD was defined as the presence of proteinuria or a value of $<60 \mathrm{~mL} / \mathrm{min} /$ $1.73 \mathrm{~m}^{2}$ for the estimated glomerular filtration rate (eGFR).

A past history of CVD included diagnosed angina pectoris, myocardial infarction, and stroke. Three office $\mathrm{BP}$ values measured in a sitting position at two clinic visits were taken by a physician or nurse using an upper arm cuff oscillometric BP device (HEM-5001; Omron Healthcare, Kyoto, Japan), and these values were averaged in the present study. 
Taki et al.: Correlation between BNP and NT-proBNP

Table 1. Patients' characteristics $(n=3,643)$

$\begin{array}{ll}\text { Age, years } & 65.0 \pm 10.6 \\ \text { Male, \% } & 46.2 \\ \text { Body mass index } & 24.2 \pm 3.5 \\ \text { Smoking, \% } & 12.1 \\ \text { Alcohol, \% } & 27.8 \\ \text { Diabetes, \% } & 24.6 \\ \text { Dyslipidemia, \% } & 42.1 \\ \text { Antihypertensive treatment, \% } & 79.1 \\ \text { Past history of CVD, \% } & 12.9 \\ \text { Estimated GFR, mL/min/1.73 m² } & 73.1 \pm 17.3 \\ \text { Clinic SBP, mmHg } & 141.4 \pm 16.4 \\ \text { Clinic DBP, mmHg } & 81.4 \pm 10.4 \\ \text { BNP, pg/mL } & 18.7(9.3-38.5) \\ \text { NT-proBNP, pg/mL } & 50.3(25.5-97.4)\end{array}$

Data are mean \pm SD or median (25-75\% percentile). CVD, cardiovascular disease; GFR, glomerular filtration rate; SBP, systolic blood pressure; DBP, diastolic blood pressure; BNP , brain natriuretic peptide; NT-proBNP, N-terminal pro-B-type natriuretic peptide.

\section{Natriuretic Peptides}

Blood and spot urine samples were collected in the morning in a fasting state at study enrollment. The plasma level of BNP (MI02 Shionogi BNP; Shionogi, Osaka, Japan) was measured by using a chemiluminescent enzyme. NT-proBNP was measured by an automated Cobas analyzer using an electrochemiluminescent immunoassay (Roche Diagnostics, Japan).

\section{Statistical Analysis}

Data are expressed as the mean $\pm \mathrm{SD}$, median (25th-75th percentile), or percentage. Because the distribution of BNP and NT-proBNP values was highly skewed, it was log-transformed before the statistical analysis. The $\chi^{2}$ test was used to compare proportions, and the unpaired $t$ test was used to compare the means for the two groups. The univariate associations were assessed using the Pearson correlation. To develop a model that is useful for predicting the value of the BNP level for a given value of the NT-proBNP level, we applied a formula using a simple linear regression between the log BNP and log NT-proBNP values. We assessed the association between log NT-proBNP and log BNP by using a multiple linear regression analysis that included age, sex, body mass index (BMI), smoking status, alcohol, diabetes, dyslipidemia, history of CVD, antihypertensive therapy and CKD. To identify multicollinearity, we assessed the variance inflation factor. Using the thresholds of BNP and NT-proBNP for individuals suspected of having heart failure as provided by the Japanese guidelines [16], we also calculated Cohen kappa coefficients to investigate the concordance of those values of BNP and NT-proBNP [17]. All statistical analyses were performed with the SPSS program, ver. 19.0 (Chicago, IL, USA).

\section{Results}

Among the 3,643 patients, 1,683 (46.2\%) were men and 1,960 (53.8\%) were women. The mean \pm SD values were as follows: age, $65.0 \pm 10.6$ years; BMI, $24.2 \pm 3.5$; clinic SBP/DBP $141.4 \pm 16.4 / 81.4 \pm 10.4 \mathrm{~mm}$ Hg; eGFR $73.1 \pm 17.3 \mathrm{~mL} / \mathrm{min} / 1.73 \mathrm{~m}^{2}$. The median $(25 \mathrm{th}-75 \mathrm{th}$ percentiles) BNP and NT-proBNP values were 18.7 (9.3-38.5) and 50.3 (25.5-97.4) pg/mL (Table 1). As shown in Supplementary Table S1 (for all online suppl. material, see www. karger.com/doi/10.1159/000485660), the included participants $(n=3,643)$ compared to the excluded subjects without BNP and NT-proBNP data $(n=667)$ had a significantly lower percentage of men ( 46.2 vs. $51.6 \%, p=0.01$ ), significantly higher dyslipidemia (42.1 vs. $32.8 \%, p<0.001)$, and significantly lower eGFR values (73.1 vs. $\left.75.4 \mathrm{~mL} / \mathrm{min} / 1.73 \mathrm{~m}^{2}\right)$. 
Fig. 1. Scatterplot of log-transformed N-terminal pro-B-type natriuretic peptide (NT-proBNP) and log-transformed B-type natriuretic peptide (BNP) values in 3,643 Japanese patients $(65 \pm 11$ years old) from the J-HOP Study.

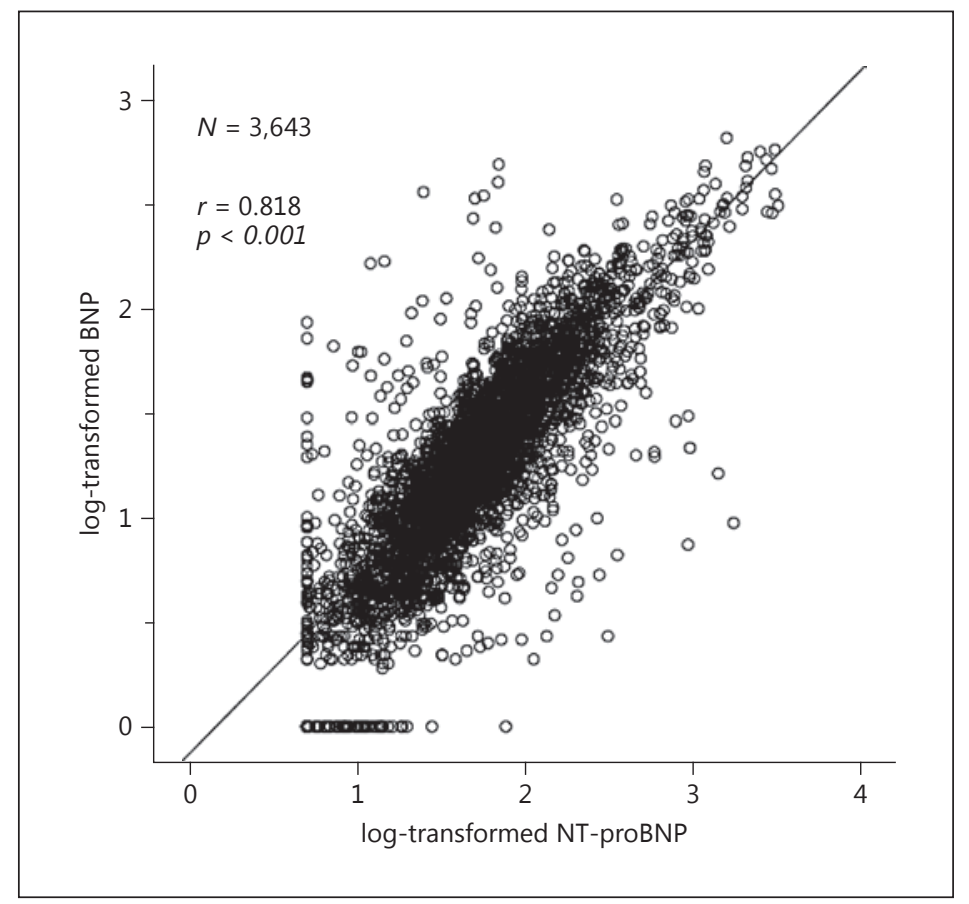

Figure 1 is the scatter plot illustrating the association between log-transformed values of BNP and NT-proBNP. There was a significant association between log-transformed BNP and log-transformed NT-proBNP $(r=0.818, p<0.001)$. The regression formula was $\mathrm{y}=$ $-0.127+0.815 \mathrm{x}$, where -0.127 was the $\mathrm{y}$-intercept and 0.815 was the slope. As an example, the predicted values of BNP (y) calculated using this formula and NT-proBNP (x) are shown in Table 2.

A multiple linear regression analysis showed that log-transformed NT-proBNP was significantly associated with log-transformed BNP (beta coefficient $=0.774, p<0.001$ ). When we also stratified the patients according to demographics ( $<65 \mathrm{vs.} \geq 65$ years, women or men, $<25$ vs. $\geq 25$ in BMI, and absence vs. presence of smoking, alcohol, diabetes, dyslipidemia, and antihypertensive medication, past history of CVD, and CKD), the significant associations between log-transformed NT-proBNP and BNP remained (all $p<0.001$ ) (Table 3).

The prevalence of the subjects with a BNP level $>200 \mathrm{pg} / \mathrm{mL}$ and that of subjects with an NT-pro BNP level $>900 \mathrm{pg} / \mathrm{mL}$ and thus suspected of having heart failure according to the 2010 Japanese Circulation Society (JCS) guidelines for the treatment of chronic heart failure were $1.8 \%(n=64)$ and 1.6\% $(n=59)$, respectively. The Cohen kappa coefficient calculated to investigate the concordance of these values was revealed to be 0.68 .

\section{Discussion}

Our findings showed that there was a significant correlation between BNP and NT-proBNP in a large Japanese population of individuals who had a history of and/or risk factors for CVD, which is a potential contributor to stage A heart failure. When the study population was stratified by individual risk factors, this association between BNP and NT-proBNP remained.

Several studies have indicated that BNP and NT-proBNP are both very useful markers for the diagnosis and prognosis of heart failure $[1,2]$. In some guidelines, these two biomarkers 
Table 2. Predicted value of BNP for a given value of NT-proBNP using the regression formula

\begin{tabular}{lccc}
\hline $\begin{array}{l}\text { NT-proBNP, } \\
\text { pg/mL }\end{array}$ & $\begin{array}{l}\text { BNP, } \\
\text { pg/mL }\end{array}$ & $\begin{array}{l}\text { NT-proBNP, } \\
\text { pg/mL }\end{array}$ & $\begin{array}{l}\text { BNP, } \\
\text { pg/mL }\end{array}$ \\
\hline 10 & 5 & 190 & 54 \\
20 & 9 & 200 & 56 \\
30 & 12 & 300 & 78 \\
40 & 15 & 400 & 99 \\
50 & 18 & 500 & 118 \\
55 & 20 & 600 & 137 \\
60 & 21 & 700 & 156 \\
70 & 24 & 800 & 173 \\
80 & 27 & 900 & 191 \\
90 & 29 & 1,000 & 208 \\
100 & 32 & 1,500 & 289 \\
110 & 34 & 2,000 & 366 \\
120 & 37 & 2,500 & 439 \\
125 & 38 & 3,000 & 509 \\
130 & 39 & 3,500 & 577 \\
140 & 42 & 4,000 & 644 \\
150 & 44 & 4,500 & 709 \\
160 & 47 & 5,000 & 772 \\
170 & 49 & 5,500 & 834 \\
180 & 51 & 6,000 & 896 \\
\hline
\end{tabular}

NT-proBNP, N-terminal pro B-type natriuretic peptide; BNP, brain natriuretic peptide.

have an equal role in the diagnostic evaluation of heart failure, based on the results of several comparisons of the two biomarkers' utility for the diagnosis or exclusion of acute heart failure $[14,16,18]$. Both the BNP and NT-proBNP levels at less than a cutoff point for the diagnosis of heart failure have also provided prognostic power for cardiovascular outcomes in general and hypertensive populations [3-5].

These previous studies may indicate that stage A heart failure patients, who are at high risk of experiencing advanced heart failure and have cardiovascular risk factors but are without symptoms, would have poor cardiovascular prognoses. However, there have been few studies about the correlation between BNP and NT-proBNP levels in large populations of individuals with the risk factor of stage A heart failure. In the 2016 European Society of Cardiology (ESC) guidelines for the diagnosis and treatment of acute and chronic heart failure, the upper limits of normal in the nonacute setting of heart failure for the BNP and NT-proBNP levels are 35 and $125 \mathrm{pg} / \mathrm{mL}$, respectively [18]. In the present study, the BNP and NT-proBNP values calculated from a simple regression formula were 38 and $125 \mathrm{pg} / \mathrm{mL}$, respectively. Although there is a lack of evidence regarding the limits of the BNP and NT-proBNP levels for the diagnosis of heart failure in the Japanese population, the 2010 JCS guidelines for the treatment of chronic heart failure demonstrated that the thresholds of BNP and NT-proBNP values for patients suspected of having heart failure were 200 and $900 \mathrm{pg} / \mathrm{mL}$, respectively [16]. In the present study, the BNP and NT-proBNP levels were 191 and $900 \mathrm{pg} / \mathrm{mL}$, respectively. In addition, the Cohen kappa coefficient was 0.68 , indicating substantial agreement [17]. Thus, our findings support the concordance of values between BNP and NT-proBNP for the threshold of heart failure status in both the ESC and JSC guidelines.

After the adjustment for demographic factors, our multiple linear regression analysis showed a significant association between BNP and NT-proBNP levels. When we stratified the population by demographic characteristics, these significant associations remained. Both 
Taki et al.: Correlation between BNP and NT-proBNP

Table 3. Association of log-transformed NT-proBNP with log-transformed BNP

\begin{tabular}{|c|c|c|c|}
\hline & $n$ & Beta coefficient $(95 \% \mathrm{CI})$ & $p$ \\
\hline All participants & 3,643 & $0.774(0.753-0.794)$ & $<0.001$ \\
\hline \multicolumn{4}{|l|}{ Age } \\
\hline$<65$ years & 1,695 & $0.796(0.766-0.826)$ & $<0.001$ \\
\hline$\geq 65$ years & 1,948 & $0.754(0.726-0.782)$ & $<0.001$ \\
\hline \multicolumn{4}{|l|}{ Sex } \\
\hline Women & 1,960 & $0.759(0.729-0.789)$ & $<0.001$ \\
\hline Men & 1,683 & $0.783(0.755-0.811)$ & $<0.001$ \\
\hline \multicolumn{4}{|l|}{ BMI } \\
\hline$<25$ & 2,312 & $0.781(0.756-0.806)$ & $<0.001$ \\
\hline$\geq 25$ & 1,331 & $0.761(0.727-0.796)$ & $<0.001$ \\
\hline \multicolumn{4}{|l|}{ Smoking } \\
\hline Absent & 3,201 & $0.768(0.746-0.790)$ & $<0.001$ \\
\hline Present & 4,42 & $0.811(0.755-0.868)$ & $<0.001$ \\
\hline \multicolumn{4}{|l|}{ Alcohol } \\
\hline Absent & 2,631 & $0.762(0.738-0.786)$ & $<0.001$ \\
\hline Present & 1,012 & $0.799(0.761-0.837)$ & $<0.001$ \\
\hline \multicolumn{4}{|l|}{ Diabetes } \\
\hline Absent & 2,631 & $0.762(0.738-0.786)$ & $<0.001$ \\
\hline Present & 1,012 & $0.799(0.761-0.837)$ & $<0.001$ \\
\hline \multicolumn{4}{|l|}{ Dyslipidemia } \\
\hline Absent & 2,109 & $0.774(0.748-0.801)$ & $<0.001$ \\
\hline Present & 1,534 & $0.772(0.740-0.804)$ & $<0.001$ \\
\hline \multicolumn{4}{|c|}{ Antihypertensive medication } \\
\hline Absent & 781 & $0.713(0.663-0.764)$ & $<0.001$ \\
\hline Present & 2,882 & $0.786(0.764-0.808)$ & $<0.001$ \\
\hline \multicolumn{4}{|c|}{ Past history of CVD } \\
\hline Absent & 3174 & $0.773(0.750-0.795)$ & $<0.001$ \\
\hline Present & 469 & $0.781(0.733-0.829)$ & $<0.001$ \\
\hline \multicolumn{4}{|c|}{ Chronic kidney disease ${ }^{a}$} \\
\hline Absent & 761 & $0.797(0.757-0.837)$ & $<0.001$ \\
\hline Present & 2,882 & $0.766(0.742-0.789)$ & $<0.001$ \\
\hline
\end{tabular}

NT-proBNP, N-terminal pro B-type natriuretic peptide; BNP, brain natriuretic peptide; BMI, body mass

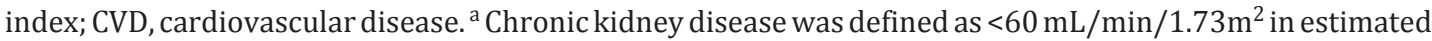
glomerular filtration rate. Beta coefficient was adjusted for age, sex, BMI, smoking, alcohol, diabetes, dyslipidemia, antihypertensive medication, past history of CVD and chronic kidney disease.

BNP and NT-proBNP have been reported to be influenced by age, gender, obesity, and renal dysfunction [10-13]. Renal dysfunction in particular has shown a significant effect on the $\mathrm{BNP} / \mathrm{NT}$-proBNP ratio because of the difference in clearance between two markers [19]. Our present findings suggest that the elevations of both BNP and NT-proBNP occur in parallel regardless of demographic characteristics.

The measurement of plasma levels of BNP is more complicated compared to that of NT-proBNP. When whole blood is used for assays, NT-proBNP is stable under a variety of storage conditions (including room temperature) for a prolonged period [20]. In the future, NT-proBNP rather than BNP might be more useful in clinical and research fields.

Our study population was predominantly men, with higher dyslipidemia and lower eGFR values compared to the excluded participants. These imbalances, or selection biases, might limit the external validity of the present findings to some extent.

In conclusion, in the dataset of a large Japanese population at risk of stage A heart failure, there was a significant association between BNP and NT-proBNP levels after adjustment and 
Taki et al.: Correlation between BNP and NT-proBNP

stratification by demographics. NT-proBNP values were elevated in parallel with BNP values in this population. Both BNP and NT-proBNP may provide equal information for ruling out heart failure and may be used as prognostic markers regardless of demographic factors.

\section{Disclosure Statement}

K. Kario has received research funding from Teijin Pharma Limited, Omron Healthcare Co., Ltd., Fukuda Denshi, Bayer Yakuhin Ltd., A\&D Co., Ltd., Daiichi Sankyo Company Limited, Mochida Pharmaceutical Co., Ltd., EA Pharma, Boehringer Ingelheim Japan Inc., Tanabe Mitsubishi Pharma Corporation, Shionogi \& Co., Ltd., MSD K.K., Sanwa Kagaku Kenkyusho Co., Ltd., Bristol-Myers Squibb K.K., and honoraria from Takeda Pharmaceutical Company Limited and Omron Healthcare Co., Ltd.

\section{References}

1 Maisel AS, Krishnaswamy P, Nowak RM, McCord J, Hollander JE, Duc P, Omland T, Storrow AB, Abraham WT, Wu AH, Clopton P, Steg PG, Westheim A, Knudsen CW, Perez A, Kazanegra R, Herrmann HC, McCullough PA: Rapid measurement of B-type natriuretic peptide in the emergency diagnosis of heart failure. N Engl J Med 2002;347:161-167.

-2 Zaphiriou A, Robb S, Murray-Thomas T, Mendez G, Fox K, McDonagh T, Hardman SM, Dargie HJ, Cowie MR: The diagnostic accuracy of plasma BNP and NTproBNP in patients referred from primary care with suspected heart failure: results of the UK natriuretic peptide study. Eur J Heart Fail 2005;7:537-541.

-3 Paget V, Legedz L, Gaudebout N, Girerd N, Bricca G, Milon H, Vincent M, Lantelme P: N-terminal pro-brain natriuretic peptide: a powerful predictor of mortality in hypertension. Hypertension 2011;57:702-709.

-4 Neeland IJ, Drazner MH, Berry JD, Ayers CR, deFilippi C, Seliger SL, Nambi V, McGuire DK, Omland T, de Lemos JA: Biomarkers of chronic cardiac injury and hemodynamic stress identify a malignant phenotype of left ventricular hypertrophy in the general population. J Am Coll Cardiol 2013;61:187-195.

5 Nakamura M, Tanaka F, Takahashi T, Makita S, Ishisone T, Onodera M, Ishibashi Y, Itai K, Onoda T, Ohsawa M, Tanno K, Sakata K, Shinichi O, Ogasawara K, Ogawa A, Kuribayashi T, Okayama A: Sex-specific threshold levels of plasma B-type natriuretic peptide for prediction of cardiovascular event risk in a Japanese population initially free of cardiovascular disease. Am J Cardiol 2011;108:1564-1569.

6 Mueller T, Gegenhuber A, Poelz W, Haltmayer M: Head-to-head comparison of the diagnostic utility of BNP and NT-proBNP in symptomatic and asymptomatic structural heart disease. Clin Chim Acta 2004;341:41-48.

7 Masson S, Latini R, Anand IS, Vago T, Angelici L, Barlera S, Missov ED, Clerico A, Tognoni G, Cohn JN: Direct comparison of B-type natriuretic peptide (BNP) and amino-terminal proBNP in a large population of patients with chronic and symptomatic heart failure: the Valsartan Heart Failure (Val-HeFT) data. Clin Chem 2006;52: 1528-1538.

$>8$ Martinez-Rumayor A, Richards AM, Burnett JC, Januzzi JL Jr: Biology of the natriuretic peptides. Am J Cardiol 2008;101:3-8.

9 de Lemos JA, McGuire DK, Drazner MH: B-type natriuretic peptide in cardiovascular disease. Lancet 2003;362: 316-322.

10 Redfield MM, Rodeheffer RJ, Jacobsen SJ, Mahoney DW, Bailey KR, Burnett JC Jr: Plasma brain natriuretic peptide concentration: Impact of age and gender. J Am Coll Cardiol 2002;40:976-982.

11 Maisel AS, Clopton P, Krishnaswamy P, Nowak RM, McCord J, Hollander JE, Duc P, Omland T, Storrow AB, Abraham WT, Wu AH, Steg G, Westheim A, Knudsen CW, Perez A, Kazanegra R, Bhalla V, Herrmann HC, Aumont MC, McCullough PA: Impact of age, race, and sex on the ability of B-type natriuretic peptide to aid in the emergency diagnosis of heart failure: Results from the breathing not properly (BNP) multinational study. Am Heart J 2004;147:1078-1084.

12 Horwich TB, Hamilton MA, Fonarow GC: B-type natriuretic peptide levels in obese patients with advanced heart failure. J Am Coll Cardiol 2006;47:85-90.

-13 McCullough PA, Duc P, Omland T, McCord J, Nowak RM, Hollander JE, Herrmann HC, Steg PG, Westheim A, Knudsen CW, Storrow AB, Abraham WT, Lamba S, Wu AH, Perez A, Clopton P, Krishnaswamy P, Kazanegra R, Maisel AS: B-type natriuretic peptide and renal function in the diagnosis of heart failure: an analysis from the breathing not properly multinational study. Am J Kidney Dis 2003;41:571-579.

14 Yancy CW, Jessup M, Bozkurt B, Butler J, Casey DE Jr, Colvin MM, Drazner MH, Filippatos GS, Fonarow GC, Givertz MM, Hollenberg SM, Lindenfeld J, Masoudi FA, McBride PE, Peterson PN, Stevenson LW, Westlake C: 2017 ACC/AHA/HFSA focused update of the 2013 ACCF/AHA guideline for the management of heart failure: a report of the American College of Cardiology/American Heart Association task force on clinical practice guidelines and the Heart Failure Society of America. Circulation 2017;136:e137-e161. 
15 Hoshide S, Yano Y, Haimoto H, Yamagiwa K, Uchiba K, Nagasaka S, Matsui Y, Nakamura A, Fukutomi M, Eguchi $\mathrm{K}$, Ishikawa J, Kario K: Morning and evening home blood pressure and risks of incident stroke and coronary artery disease in the Japanese general practice population: the Japan Morning Surge-Home Blood Pressure study. Hypertension 2016;68:54-61.

16 The guidelines for the treatment of chronic heart failure (Japanese Circulation Society 2010). http://www.jcirc.or.jp/guideline/ (in Japanese).

17 Landis JR, Koch GG: The measurement of observer agreement for categorical data. Biometrics 1977;33:159174.

18 Ponikowski P, Voors AA, Anker SD, Bueno H, Cleland JG, Coats AJ, Falk V, Gonzalez-Juanatey JR, Harjola VP, Jankowska EA, Jessup M, Linde C, Nihoyannopoulos P, Parissis JT, Pieske B, Riley JP, Rosano GM, Ruilope LM, Ruschitzka F, Rutten FH, van der Meer P: 2016 ESC guidelines for the diagnosis and treatment of acute and chronic heart failure: the task force for the diagnosis and treatment of acute and chronic heart failure of the European Society of Cardiology (ESC). Developed with the special contribution of the Heart Failure Association (HFA) of the ESC. Eur J Heart Fail 2016;18:891-975.

19 Vickery S, Price CP, John RI, Abbas NA, Webb MC, Kempson ME, Lamb EJ: B-type natriuretic peptide (BNP) and amino-terminal proBNP in patients with CKD: relationship to renal function and left ventricular hypertrophy. Am J Kidney Dis 2005;46:610-620.

20 Azzazy HM, Christenson RH, Duh SH: Stability of B-type natriuretic peptide (BNP) in whole blood and plasma stored under different conditions when measured with the Biosite Triage or Beckman-Coulter Access systems. Clin Chim Acta 2007;384:176-178. 